\title{
Availability, Accessibility and Proper Use of Personal Protective Equipment in Wards at Queen Elizabeth Central Hospital (QECH) Blantyre, Malawi: An Observational Study
}

\author{
Davie Madziatera, Kondwani Stanslas Msofi, Thokozani V Phiri, Samuel Devaughn Mkandawire, \\ Amy Comber
}

Kamuzu Central Hospital

Email: daviemadzi@gmail.com or daviewater@yahoo.com

Background
The purpose of this study was to evaluate the availability, accessibility and proper use of personal protective equipment (PPE) in the
wards at Queen Elizabeth Central Hospital (QECH).
Methods: We conducted an observational study with a cross-section design. Convenience sampling method was used for selection
of healthcare workers (HCWs) in wards. HCWs filled a checklist on accessibility of PPEs and they were observed on proper use of
PPE while conducting clinical procedures. Nurse ward in-charge was asked to fill out a checklist on availability of PPE in their ward.
Results
PPE was available in $75.8 \%$ of wards, not available in $12.5 \%$. Goggles were absent in $70.8 \%$ of wards. PPEs were $71.4 \%$ accessible and
$28.6 \%$ inaccessible to healthcare workers in the wards. The most inaccessible PPEs were goggles $(83.2 \%)$ and footwear $(73.7 \%)$ while
facemasks, sterile and non-sterile gloves and aprons were readily accessible. Non sterile gloves were $100 \%$ available and accessible.
Only $13.5 \%$ of the HCWs had good compliance with PPE standard procedures. The average PPE compliance score of those who had
been trained was $6 \%$ greater than those who were not trained.
Conclusion
This study identified areas of improvement in healthcare system delivery regarding standard precautions with emphasis on PPE.
Improvements in training during professional college education and in-service refresher training could improve compliance with
appropriate use of PPE for relatively low cost. Management support could improve availability and accessibility of PPE in the wards
at QECH, with active supervision to improve adherence levels to personal protective equipment usage. The study can also help in the
development of policies and guidelines regarding PPE usage by showing that most HCWs need to be trained in proper PPE usage.

Keywords: infection prevention, hospital acquired infections, personal protective equipment, healthcare worker, compliance of standard precautions

\section{Introduction}

Healthcare-associated infections (HAIs) remain as the most frequent adverse event in any healthcare delivery system and affect millions of people each year, leading to significant morbidity and mortality ${ }^{1}$. HAIs are infections acquired within a healthcare facility. The risk of HAIs can be reduced through practicing standard precautions (SPs), including use of personal protective equipment (PPE), which is considered a cost-effective strategy for combatting HAIs ${ }^{2-5}$.

These SPs are work practices that are required to achieve a basic level of infection control ${ }^{6}$. They assume that all blood and body substances are potentially infectious hence are applied to all patients at all times regardless of their diagnosis and infectious status ${ }^{4,6,7}$. They aim to prevent transmission of infections including HIV, hepatitis B and hepatitis $\mathrm{C}^{6}$. SPs involve work practices such as personal hygiene particularly hand washing before and after contact with clients, appropriate reprocessing of re-usable equipment and instruments, management of contaminated linen and waste, and the use of PPEs6. PPEs are specialized clothing worn by HCWs in clinical work for protection against infection ${ }^{2,8}$. They include gloves, masks or respirators, aprons, eye protectors and footwear ${ }^{2,8,9}$. These provide a physical barrier when the health worker is in contact with blood, body fluids or discharges, non-intact skin or mucous membranes, soiled items and contaminated surfaces or equipment which might be infectious ${ }^{2-4,9}$.

In order for PPEs to be effective in infection prevention (IP), they have to be readily available, accessible (easily found for use), appropriately selected and properly used. Poor availability of PPEs leads to poor selection of PPE, putting the HCWs at risk of contracting HAIs due to inadequate protection $^{10}$. There are guidelines as recommended by Centre for Disease Control and Prevention (CDC) ${ }^{2}$, National Health Service $(\mathrm{NIH})^{11}$ and World Health Organization $(\mathrm{WHO})^{12}$ that describe steps on how each PPE has to be put on or removed and how the HCWs have to conduct themselves while wearing a particular PPE. Failure to follow these guidelines is regarded as poor compliance with the appropriate use of PPEs. Improper use of PPEs can lead to transmission of HAIs which can complicate a patient's condition, leading to a longer hospital stay with economic consequences for the patient and family ${ }^{13-15}$.

Selection of appropriate PPE is also based on personal perception of risk of infection and training in PPE usage $e^{2,4}$. There is a relationship between knowledge on the elements of standard precautions and having attended formal training on infection prevention however, HCWs still show knowledge 
gaps despite being trained which contribute to low adherence levels16. Adherence to infection prevention and control guidelines is critical to improving the quality of hospital care based on their efficacy in reducing the occurrence of infections that compromise patients' outcomes and the health of $\mathrm{HCWs}^{17}$.

Physiotherapists (PTs) like other clinical staff such as nurses and clinicians, frequently come into contact with patients and thus have many opportunities to transmit pathogens ${ }^{18}$. Physiotherapy services can be provided either at the bedside or in a central therapy unit. PTs get involved in the rehabilitation of patients who may have one or more impairments or disabilities at the time of admission that increases the risk of infection ${ }^{19}$. Factors such as incontinence, skin breakdown, co-morbidity, immobility, respiratory infections like Pneumonia and Tuberculosis, and age are all associated with increased risk of infection in the rehabilitation population ${ }^{19}$. This demands the appropriate use of infection prevention and control measures to ensure the health and safety of patients, healthcare workers, and the broader community ${ }^{16,17}$.

The prevalence of HAIs in developing countries varies from $5.7 \%$ to $19.1 \%{ }^{20}$. The incidence of Intensive Care Unit (ICU)acquired infection is at least 2-3 fold higher in low-income countries than in high-income countries ${ }^{20}$. These alarming figures raise questions on compliance with SPs of which PPE usage is included since it is a cost effective strategy to prevent HAIs4 in developing countries like Malawi where resources are very limited ${ }^{21}$. The purpose of this study was to evaluate on how available and accessible PPEs are, and how HCWs adhere to appropriate use of PPEs in the wards at QECH. This is to help promote high-quality health services at QECH and other healthcare facilities in the area on infection prevention. Therefore the objectives of this study were: (1) to examine the availability of PPEs in wards at QECH; (2) to examine accessibility of PPEs in wards at $\mathrm{QECH}$; (3) to assess proper putting on and removing of PPEs of health workers in the wards at QECH; and (4) to ascertain whether HCWs working at QECH were trained in proper usage of PPEs.

\section{Methodology \\ Type of Study}

This was an observational study with a cross-section design.

\section{Setting}

This research was conducted from 10th November 2017 to 17th November 2017 in wards at Queen Elizabeth Central Hospital (QECH), a tertiary hospital which is located in Blantyre, Malawi, a country in Sub-Saharan Africa. It is the largest government referral hospital in the country with a total of thirty wards containing 1,250 inpatient beds and three private wards with additional 122 inpatient beds. The study was conducted in 24 wards out of the 30 wards. QECH was selected because the investigators had observed poor adherence to SPs during clinical practical sessions.

\section{Sample Size Calculation}

We used a population proportion formula ${ }^{22}$ to determine the sample size. This was made with $95 \%$ confidence interval and the margin of error was predetermined to 0.1 . The proportion of HCWs with good compliance of PPE usage is unknown so it was set at 0.5 . This gave us a minimum sample size of 96 health workers. The sample size was estimated using the following formula:

$$
n=\frac{p(1-p) z_{1-\propto / 2}^{2}}{d^{2}}
$$

Where:

$\mathrm{n}$ is the sample size

$z^{1}(1-\alpha / 2)$ is the standard normal variant (at $5 \%$ type I error it is 1.96)

$\mathrm{d}$ is the margin of error

\section{Sampling Strategy}

The wards were selected using simple random sampling and the participants were sampled using convenient sampling. Names of all wards at QECH were written on pieces of paper and placed in a small bag. Investigators selected wards by picking a piece of paper each day. The chosen pieces of paper were not replaced in the bag. At the ward investigators requested names of all available $\mathrm{HCW}$ from the nurse incharge. The HCWs were numbered and these numbers were written on pieces of paper and put in a bag. One number was randomly selected and the investigators approached every third person from the selected number to participate in the study. Investigators were supposed to assess $6 \mathrm{HCWs}$ in each ward.

Caution was taken not to observe same participant twice since some health workers work in several wards. The investigators asked the HCWs if they had already participated in this study before writing numbers on pieces of paper. HCWs who had already participated were not included in sampling population.

\section{Inclusion criteria for availability of PPEs}

\section{Nurse Manager or nurse in-charge}

Inclusion criteria for accessibility and proper use of PPEs:

Health workers at QECH including allied health professions working in wards involved in the provision of direct health care who are exposed to blood, body fluids, secretions and infectious diseases.

Health workers' consent.

\section{Exclusion criteria for accessibility and proper use of PPEs:}

Health workers with managerial and supervising duties were excluded from this study.

Students were excluded as they may have not yet completed their professional education.

\section{Health workers working in theatre. \\ Survey Instruments and Data Collection}

Data was collected using two checklists. Nurse Manager or ward in-charge was asked to fill out the checklist on availability of PPEs in that ward. Availability was defined as the state of being present ${ }^{23}$. The sister in charge rated availability as: 0 - Absent, 1 - Inadequate, available to less than half of those who need it, 2 - Adequate: present and readily available to almost everyone in need of them ${ }^{24}$. The other checklist had two parts, one part was filled by the participant on demographic data and accessibility of PPEs and another part was filled by the investigators with data from 
observations on procedure done by the participants according to guidelines by CDC $(2004)^{2}$, National Health Service (2010) ${ }^{11}$ and WHO $(2004)^{12}$. Accessibility was defined as availability of a resource within reasonable reach of those who need them $^{25}$. The participants recorded "Yes" if PPE was accessible and "No" if PPE was not accessible.

Prior to the collection of data, investigators were trained on how to use the checklist to ensure standardization in collection of data. Participants were approached and upon giving a signed informed consent, they completed the relevant checklist and then they were observed carrying out a procedure related to patient care and the investigators assessed proper use of PPEs. Proper PPE usage was observed according to guidelines adopted from CDC $(2004)^{2}$, National Health Service (2010)11 and WHO (2004)12.

\section{Data Entry and Analysis}

Data was entered and analyzed using EPI INFO version 3.5.4, Chi-square was used to compare proportions of categorical variables. Logistic regression analysis was computed to identify variables having a significant association with the dependent variable. The confidence interval of $95 \%$ was used to determine the strength of association between dependent and independent variables. For this study all variables having a value of less than or equal to 0.05 in the logistic regression model were considered as significantly associated variables. Data was categorized depending on the level of adherence to proper use of PPEs such as poor and good. Although there are no absolute thresholds for adequate levels of adherence, we based our threshold on variables from the infection control adherence work of Berhe et al $(2005)^{26}$ and categorized adherence as "good" based on a threshold of greater than or equal to $80 \%$. Data was compared among different PPEs and among different health professions. Patient diagnosis and procedure being observed were taken note and used to cross-check if there was adequate protection using the guidelines mentioned above.

\section{Results}

\section{Demographic Data}

During the study period, 96 participants were observed of which $65 \%$ (62) were females. Based on professions, $4 \%$ (4) were nursing aides (auxiliary nurses and patient attendants), $20 \%$ (19) were physicians, $3 \%$ (3) were dental therapists, 66 $\%$ (63) were Nurses or Midwives, 7 \% (7) were rehabilitation personnel (physiotherapists and rehabilitation technicians). Some of the professions were grouped based on their skill set. Mean age of the participants was 32.4 years ranging

- Accessible Not Accessible
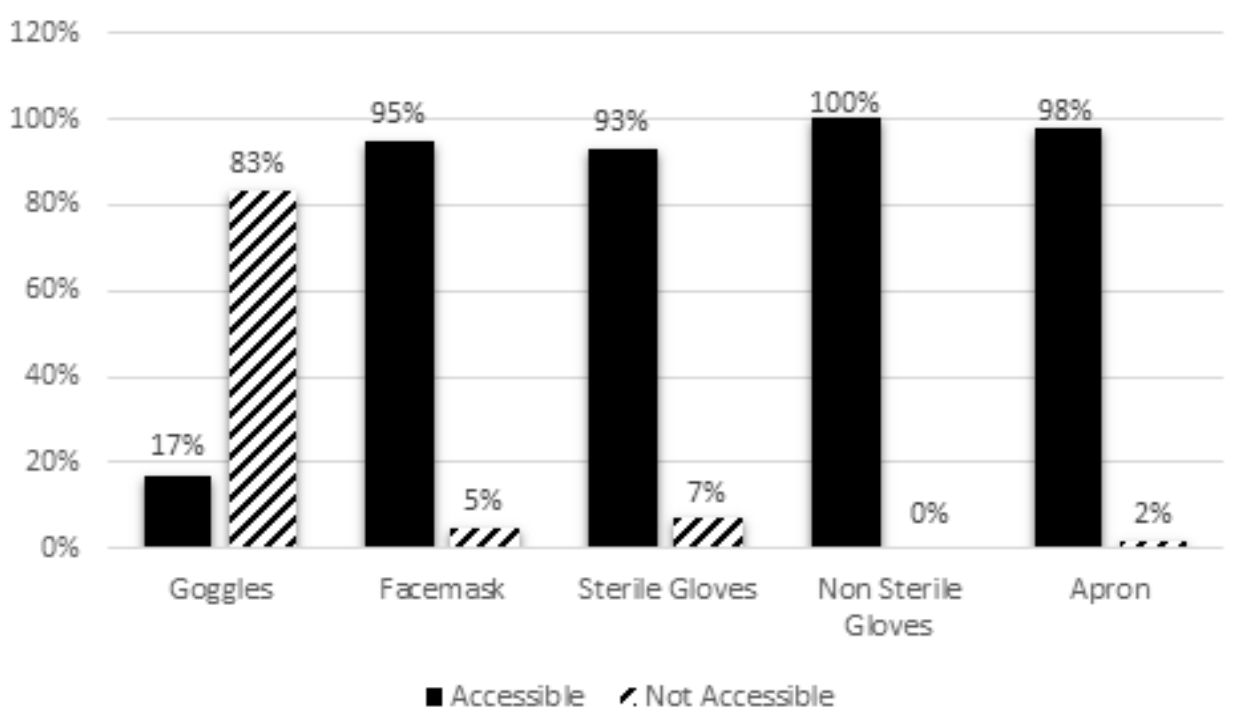

$100 \%$

Apron

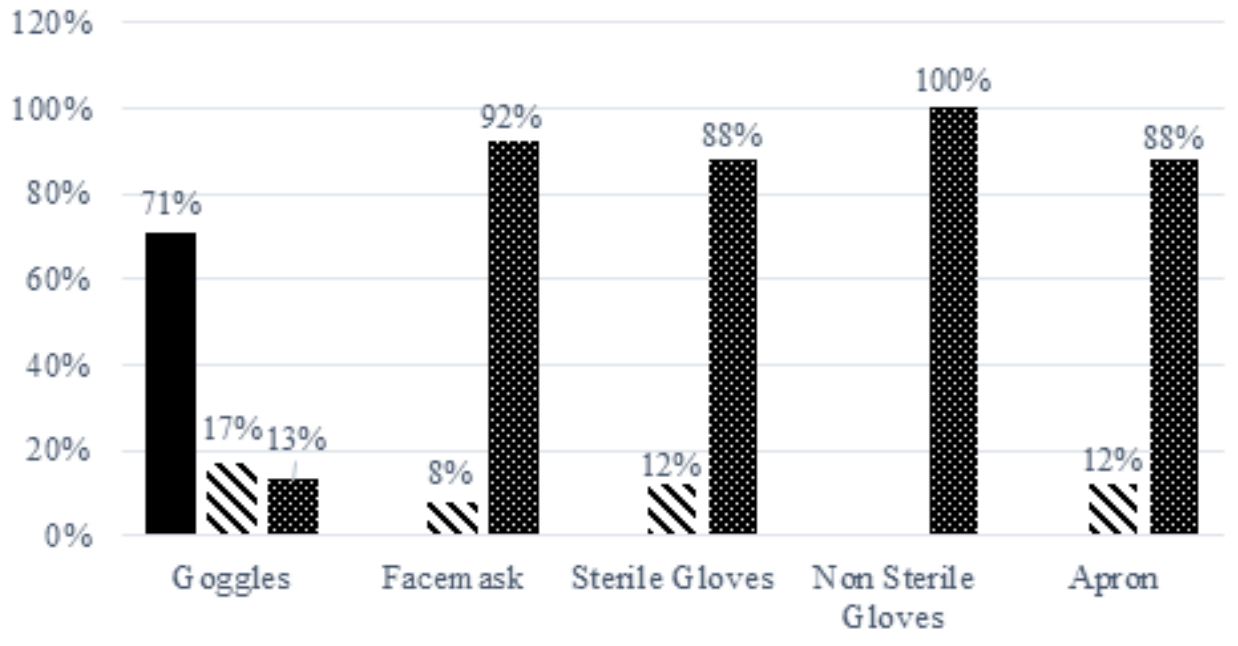

Gloves

Adequately Available

\section{Graph I: availability of PPE's in wards at QECH}

\section{Graph II: show accessibility of PPEs in wards at QECH}

from 20 to 70 years old. The study was conducted in 24 $(80 \%)$ wards of QECH. Table I shows the demographic characteristics of recruited HCWs working at QECH.

\section{Training}

This study found that $33 \%$ of participants had been trained or received refresher training in the past 3 years in the proper use of PPEs. Table II shows percentages per profession. Mean years of experience was 7.4 years ranging from 0 to 45 years. Those who were not trained had 0.6 years of experience greater than those who had been trained. The statistical correlation between training and years of experience has a P-value of 0.1441.

\section{Adherence Levels}

Only $14 \%$ of HCWs adhered to PPE usage at the level of greater than or equal to $80 \%$ of proper PPE usage. Whereof $24 \%$ were males and $8 \%$ were females. Table III shows percentages of HCWs per profession per PPE who had a good adherence level of which $19 \%$ of HCWs had training and $11 \%$ did not receive training. HCWs who received training scored an average of $6 \%$ greater than those who were not trained. 
Table I: showing demographic characteristics of the recruited HCWs working at Queen Elizabeth Central Hospital in Malawi.

\begin{tabular}{|c|c|c|c|}
\hline Variable & Category & Frequency & Percentage \\
\hline \multirow{6}{*}{ Age } & $<=20$ & 1 & $1 \%$ \\
\hline & $>20-30$ & 55 & $57 \%$ \\
\hline & $>30-40$ & 26 & $27 \%$ \\
\hline & $>40-50$ & 4 & $4 \%$ \\
\hline & $>50-60$ & 7 & $7 \%$ \\
\hline & $>60-70$ & 3 & $4 \%$ \\
\hline \multirow[t]{2}{*}{ Sex } & Female & 62 & $65 \%$ \\
\hline & Male & 34 & $35 \%$ \\
\hline \multirow{5}{*}{ Profession } & Nursing Aides & 4 & $4 \%$ \\
\hline & Clinician & 19 & $20 \%$ \\
\hline & Dental Therapist & 3 & $3 \%$ \\
\hline & Nurse/Midwife & 63 & $66 \%$ \\
\hline & $\begin{array}{l}\text { Rehabilitation } \\
\text { Personnel }\end{array}$ & 7 & $7 \%$ \\
\hline \multirow{6}{*}{$\begin{array}{l}\text { Work } \\
\text { Experience }\end{array}$} & $<=0$ & 17 & $18 \%$ \\
\hline & $>0-10$ & 57 & $61 \%$ \\
\hline & $>10-20$ & 11 & $12 \%$ \\
\hline & $>20-30$ & 3 & $3 \%$ \\
\hline & $>30-40$ & 3 & $3 \%$ \\
\hline & $>40-50$ & 3 & $3 \%$ \\
\hline \multirow{25}{*}{$\begin{array}{l}\text { Wards } \\
\text { Assigned }\end{array}$} & $\begin{array}{l}1 \mathrm{~A} \text { (Maternity } \\
\text { Ward) }\end{array}$ & 1 & $1.0 \%$ \\
\hline & $\begin{array}{l}\text { 2A (Oncology } \\
\text { Ward) }\end{array}$ & 6 & $6.3 \%$ \\
\hline & 2B (Dialysis Unit) & 6 & $6.3 \%$ \\
\hline & 3A (TB Ward) & 2 & $2.1 \%$ \\
\hline & $\begin{array}{l}\text { 3B (Male Medical } \\
\text { Ward) }\end{array}$ & 5 & $5.2 \%$ \\
\hline & $\begin{array}{l}\text { 4A (Female } \\
\text { Medical Ward })\end{array}$ & 5 & $5.2 \%$ \\
\hline & $\begin{array}{l}\text { 5A (Male Surgical } \\
\text { Ward) }\end{array}$ & 4 & $4.2 \%$ \\
\hline & $\begin{array}{l}\text { 5B (Female } \\
\text { Surgical Ward) }\end{array}$ & 3 & $3.1 \%$ \\
\hline & $\begin{array}{l}\text { 6A (Male } \\
\text { Orthopaedics } \\
\text { Ward) }\end{array}$ & 3 & $3.1 \%$ \\
\hline & Antenatal Ward & 1 & $1.0 \%$ \\
\hline & Burns Ward & 7 & $7.3 \%$ \\
\hline & Dental Ward & 5 & $5.2 \%$ \\
\hline & $\begin{array}{l}\text { Eye Nose and } \\
\text { Throat Ward }\end{array}$ & 1 & $1.0 \%$ \\
\hline & GYNAE & 5 & $5.2 \%$ \\
\hline & $\begin{array}{l}\text { Intensive Care } \\
\text { Unit }\end{array}$ & 3 & $3.1 \%$ \\
\hline & Labor Ward & 6 & $6.3 \%$ \\
\hline & Moyo Ward & 1 & $1.0 \%$ \\
\hline & $\begin{array}{l}\text { Neuro Surgery } \\
\text { High Dependence } \\
\text { Unit }\end{array}$ & 3 & $3.1 \%$ \\
\hline & Nursery Surgical & 3 & $3.1 \%$ \\
\hline & Oncology Ward & 6 & $6.3 \%$ \\
\hline & $\begin{array}{l}\text { Paediatric } \\
\text { Orthopaedic }\end{array}$ & 1 & $1.0 \%$ \\
\hline & $\begin{array}{l}\text { Paediatric Special } \\
\text { Ward }\end{array}$ & 8 & $8.3 \%$ \\
\hline & $\begin{array}{l}\text { Paediatric } \\
\text { Surgical }\end{array}$ & 3 & $3.1 \%$ \\
\hline & $\begin{array}{l}\text { Physiotherapy } \\
\text { Department }\end{array}$ & 4 & $4.2 \%$ \\
\hline & Postnatal Ward & 4 & $4.2 \%$ \\
\hline
\end{tabular}

Table II: shows percentage of HCWs that were trained in PPE usage in the past 3 years

\begin{tabular}{|l|l|}
\hline PROFESSIONS & Trained (Percentage) \\
\hline Nursing Aides & $1 / 3 \quad(33 \%)$ \\
\hline Clinician & $7 / 19(37 \%)$ \\
\hline Dental Therapist & $1 / 3(33 \%)$ \\
\hline Nurse/Midwife & $19 / 63(30 \%)$ \\
\hline Rehabilitation Personnel & $4 /_{7}(57 \%)$ \\
\hline All HCWs & $32 / 96 \%)$ \\
\hline
\end{tabular}

Table III: Adherence of PPE Usage at $>=80 \%$ per profession per PPE

\begin{tabular}{|c|c|c|c|c|c|}
\hline PPE & PHYSICIANS & NURSES & DT & REHAB & NSA \\
\hline Goggles & $\begin{array}{ll}\% & (0 \%)\end{array}$ & $1 / 2 \quad(50 \%)$ & NA & NA & NA \\
\hline Facemask & $3 / 5(60 \%)$ & $15 / 22(68 \%)$ & $\%(0 \%)$ & $\%,(0 \%)$ & $1 / 3(33 \%)$ \\
\hline Non Sterile Gloves & $6 / 14 \quad(43 \%)$ & $19 / 52(37 \%)$ & $\%(0 \%)$ & $\%(0 \%)$ & $\%(10 \%)$ \\
\hline Sterile Gloves & $3 / 7 \quad(43 \%)$ & $21_{11}(18 \%)$ & $\%(0 \%)$ & NA & $\%(0 \%)$ \\
\hline Apron & $5 / 9 \quad(56 \%)$ & $22 I_{53}(42 \%)$ & $\%(0 \%)$ & $11 / 6(17 \%)$ & $2 / 4(50 \%)$ \\
\hline Footwear & ${ }_{10}^{10}(53 \%)$ & $13 / 63(21 \%)$ & $3 / 3(100 \%)$ & $1 / / 7(14 \%)$ & $21 /(50 \%)$ \\
\hline Overall & $5 / 19(26 \%)$ & $8 / 63(13 \%)$ & $\%(0 \%)$ & $\%(0 \%)$ & $\%(10 \%)$ \\
\hline
\end{tabular}

Table IV: HCWs who did not use PPEs in procedures needing PPEs

\begin{tabular}{|l|l|l|l|}
\hline PPE & $\begin{array}{l}\text { HCWS WHO DID } \\
\text { NOT USE PPE's }\end{array}$ & $\begin{array}{l}\text { PROCEDURES } \\
\text { NEEDING PPE's }\end{array}$ & PERCENTAGE \\
\hline Goggles & 4 & 7 & $57 \%$ \\
\hline Facemask & 8 & 39 & $23 \%$ \\
\hline Sterile Gloves & 9 & 29 & $31 \%$ \\
\hline Non Sterile Gloves & 2 & 80 & $3 \%$ \\
\hline Apron & 20 & 94 & $21 \%$ \\
\hline
\end{tabular}

Table IV: HCWs who did not use PPEs in procedures needing PPEs

\begin{tabular}{|l|l|l|l|l|l|}
\hline & \multicolumn{3}{|l|}{$\begin{array}{l}\text { How available PPEs were to the HCW in } \\
\text { the ward who did not use them }\end{array}$} & \multicolumn{2}{l|}{$\begin{array}{l}\text { How accessible PPEs were } \\
\text { to the HCW in the ward who } \\
\text { did not use them }\end{array}$} \\
\hline PPE & $\begin{array}{l}\text { Adequately } \\
\text { Available }\end{array}$ & $\begin{array}{l}\text { Inadequately } \\
\text { Available }\end{array}$ & $\begin{array}{l}\text { Not } \\
\text { Available }\end{array}$ & Accessible & $\begin{array}{l}\text { Not } \\
\text { Accessible }\end{array}$ \\
\hline Goggles & 2 & 2 & 0 & 2 & 2 \\
\hline Facemask & 8 & 0 & 0 & 8 & 0 \\
\hline $\begin{array}{l}\text { Sterile } \\
\text { Gloves }\end{array}$ & 6 & 4 & 0 & 7 & 3 \\
\hline $\begin{array}{l}\text { Non Sterile } \\
\text { Gloves }\end{array}$ & 2 & 0 & 0 & 2 & 0 \\
\hline Apron & 12 & 3 & 0 & 11 & 4 \\
\hline
\end{tabular}

\section{PE Selection}

Although some procedures required the use of PPEs, the HCWs did not use them. This study found that $57 \%$ did not use goggles, $23 \%$ did not use face masks, $31 \%$ did not use sterile gloves, $3 \%$ did not use non sterile gloves and $21 \%$ did not use aprons as shown in Tables IV and $\mathrm{V}$ that relates availability and accessibility of PPEs in the wards in which the PPEs were not used. 


\section{Hand hygiene}

HCWs who performed hand hygiene before putting on of PPEs were 13\% and those who performed hand hygiene after removing of PPEs were 45\%.

\section{Incorrect Practices}

Most of the bad practices which led to poor adherence were: not wearing PPEs during clinical procedure while they were needed, not performing hand hygiene before putting on and after removing of PPEs, reusing single-use PPE, using PPEs beyond their appropriate time of use, wearing facemasks around the neck, poor putting on technique of sterile gloves, assisting other patients while wearing same gloves, touching instruments, surfaces and doorknobs with contaminated gloves, wearing PPEs too early before a clinical procedure and wearing inappropriate footwear which was neither well covering nor fluid resistant.

\section{Availability of PPEs}

The study was done in 24 wards. PPEs were $76 \%$ adequately available, $13 \%$ inadequately available and $11 \%$ unavailable in the wards. Facemask, sterile and non-sterile gloves, and aprons were readily available while goggles were in short supply in the wards.

\section{Accessibility of PPEs}

In this study, PPEs were $72 \%$ accessible and $29 \%$ not accessible to HCWs in the wards. The most not accessible PPEs were goggles $(83 \%)$ and footwear (74\%) while facemasks, sterile and non-sterile gloves and aprons were readily accessible. Non-sterile gloves were completely available and accessible

Graph II shows how accessible these PPEs were in the wards.

\section{Discussion}

This study sought to evaluate the availability, accessibility and proper use of PPEs in the wards at QECH. The results demonstrate a critical lack of job-specific training in PPE usage among HCWs, unavailability of some PPEs which are essential for IP and perilous deficits in knowledge and adherence levels to proper usage of PPEs. Despite these deficiencies, non-sterile gloves were satisfactorily and readily available and some $\mathrm{HCW}$ s still managed to use PPE appropriately.

Some professions were less represented in this study hence their involvement in this study would not be a true reflection of their profession. However, their participation is a reflection of HCWs in general. There were 4 nursing aides, 3 dental therapists, and 7 rehabilitation personnel. This was due to their scarce availability in the wards and sampling calculations which did not consider each profession.

\section{Availability and Accessibility of PPEs}

Availability of PPE is necessary for it to be used. Mostly more than one PPE is required for protection during a clinical procedure ${ }^{27,28}$, so all PPEs have to be consistently available in the wards. In Nigeria, it was found that not all PPEs are always available in most healthcare facilities ${ }^{27}$. In Ghana, Japiong et al did find that gloves were satisfactorily available while goggles and aprons were partially available ${ }^{24}$ Our research findings were similar since sterile and nonsterile gloves, facemasks and aprons were readily available while goggles were available in short supply.

It is argued that conditions are often better in secondary and tertiary health-care facilities compared to primary health centres $^{27}$. This may be because of increased manpower in secondary and tertiary facilities, increased awareness and demand for PPEs, and increased government funding to secondary and tertiary healthcare facilities ${ }^{27}$. This study was done at a tertiary hospital in Malawi which is supposed to be well resourced at all times ${ }^{27}$ but our findings showed that some PPEs were lacking in some wards except for nonsterile gloves that were satisfactorily available.

\section{Accessibility of PPEs}

HCWs need direct access to PPE in order to follow standard precautions $(\mathrm{SP})^{29}$. Sometimes $\mathrm{PPE}$ is stored or even locked far away from the place nursing care is provided, making their use impossible under certain situations like in emergency situations ${ }^{10}$. Studies have shown that PPEs are not always accessible and HCWs who do not have accessible PPE were less likely to comply with $\mathrm{SPs}^{4}$. Our findings showed that sterile and non-sterile gloves, facemasks and aprons were accessible while googles were not. On the other hand, it is argued that unless a healthcare worker has a favourable attitude towards complying with SPs, he/she might take the absence of certain modalities and equipment as an advantage not to practice recommended guidelines ${ }^{4}$. So while accessibility is an area of interest when considering compliance of PPE usage, there are also other factors like attitude and knowledge which guide perception of risk of infection and ultimately PPE usage compliance , $^{3,17,27}$.

\section{Adherence Levels}

In this study, the overall adherence levels to proper use of PPEs among HCWs was very low (14\%). Similar findings were found in studies done in Nigeria ${ }^{27}$, Ethiopia ${ }^{4}$, and India30 such that the proportion of HCWs who always complied with appropriate use of PPEs ranged from 4.3\% to $18.1 \%$. One of the possible factors for poor adherence to PPE usage is the lack of training in proper usage of $\mathrm{PPEs}^{27,30}$. It is stated in one meta-analysis ${ }^{31}$ that training improves compliance with PPE usage. In this study most HCWs were not trained or did not receive any form of inservice training in infection prevention in the past 3 years and this explains the low compliance in PPE usage. It is reported that compliance with IP practices is poor among HCWs despite their awareness of its rationale ${ }^{13,14,32}$. HCWs have cited various reasons for noncompliance, including insufficient time, discomfort, unavailable and inaccessible supplies, lack of knowledge, carelessness, forgetfulness, lack of habit, perception of a low risk of infection, and disbelief in its use $\mathrm{e}^{10,13,15,33}$. These factors are aggravated by precarious infrastructure, organizational aspects of work, lack in knowledge due to the inexistence of permanent education, work overload, physical fatigue and lack of time $e^{1,15}$.

Interventions tried in other countries to increase the compliance with appropriate PPE usage include but not limited to in-service training on SPs beyond ordinary level ${ }^{34}$, preservice training by inclusion of SPs in educational curricula35, and availability of $\mathrm{PPE}^{36,37}$.

\section{PPE selection}

Different patient care procedures require different PPEs depending on the degree of risk of infection ${ }^{38}$. Hence the need to select appropriate PPE for a particular procedure to ensure adequate protection against infections to the patient and $\mathrm{HCW}^{24}$. In this study, some HCWs had problems in the selection of appropriate PPE for a clinical procedure which Https://dx.doi.org/10.4314/mmj.v32i3.4 
may be due to lack of training or availability or accessibility or individual factors such as negligence ${ }^{3}$ of which these factors were not part of this study. Studies have shown that some HWCs never wear some PPEs because some perceive that some procedures have minimal skin exposure hence reduced risk of contamination, others do not wear PPEs because they are unavailable ${ }^{3,10,27}$, another reason is that there are no protocols on what to wear in which clinical procedure ${ }^{31}$ and others do not use PPEs just because fellow HCWs are not using them ${ }^{4,39}$. Our findings show that despite gloves, aprons and facemasks being available and accessible, HCWs choose not to use them, implying that a good number of the HCWs had reasons beyond availability and accessibility of the PPEs in the wards.

\section{Training}

HCW's have to be trained on how to appropriately use PPEs. Research papers have found that compliance with PPE usage is correlated to years of experience and training ${ }^{4,10}$. Lack of training is known to diminish compliance of PPE usage ${ }^{30}$. The poor compliance with proper PPE usage may have been contributed by less trained HCWs.

\section{Training versus Professional College Education}

In this study, professional college education was considered as a form of training in PPE usage because training in IP is included during college education ${ }^{14,27}$. Literature shows that college education does not provide effective training in the proper use of PPEs and students in healthcare professions have shown low compliance of PPE usage ${ }^{40}$. Rehabilitation personnel had a high percentage of trained personnel (57 $\%$ ) but none of them had a good adherence level (overall adherence of $>=80 \%$ ). All of them except one had just graduated hence the low levels of adherence the training was in form of college of education.

\section{Gender}

Some studies have found that female HCWs have better compliance due to a natural tendency of female workers to obey organizational rules and regulations most often and also to their extra caution against infections ${ }^{4}$. This is to imply that female HCWs are more likely to comply with SPs as compared to male $\mathrm{HCWs}^{4}$. Findings of this research were contradictory such that males had better adherence levels than females.

\section{Hand Hygiene}

Our research also collected data on hand hygiene that is done before and after the use of PPEs and it is a significant component in SPs of IP. Our findings were in agreement with research findings in Africa and western countries which is that most HCWs do not perform hand hygiene before and after wearing PPEs, or before and after touching patients even in instances where PPE was not used ${ }^{4,41}$. Our findings showed that only a handful of HCWs perform hand hygiene. Our research did not assess the availability of soap or water or sink facilities hence we were unable to make conclusions on why hand hygiene was not done. Studies have cited the following reasons for non-compliance with hand washing among HWCs: HCWs forgot inconvenient placement of hand rub dispenser or sink; broken dispenser or sink no hand rub in the dispenser or missing soap at sink; HCWs being distracted with medical emergencies; perception that wearing gloves negate need for hand hygiene; proper use of gloves slows down work process; ineffective education; inadequate safety culture that doesn't stress the need for everyone to perform hand hygiene; HCWs do not remind each other to clean hands; isolation area: special circumstances related to gowning and gloving; skin irritation from the cleaning product; bedside procedure requiring frequent room entry and exit; admitting or discharging patients requires frequent room entry and exit; hand hygiene data are not collected or are inaccurate or infrequently reported; hand cleaning product feels unpleasant; HCW being too busy; emergency situation; and workflow not conducive for proper hand hygiene $e^{8,11,17,21,40}$.

\section{Footwear}

The choice of footwear is driven by a concern for HCW safety and a decrease in the risk of exposure to blood or other potentially infectious material, sharps injuries, and slipping ${ }^{19}$. Footwear is usually personal unless in special wards like the labour ward where the hospital provide plastic boots to be used during the delivery of babies. Although restrictions on HCWs footwear are influenced by a desire to meet patients' preferences for appropriate attire, most are driven by concerns for HCW safety. When HCW safety concerns or patient preference conflict with a HCW's desire for fashion, a facility's dress code can be the arbiter of footwear ${ }^{42}$.

This study was looking at whether the footwear was both well covering and fluid-resistant $t^{6}$. Footwear with open heels and or holes across the top can increase the risk of harm to the person wearing them due to more direct exposure to blood/body fluids or of sharps being dropped ${ }^{32}$. Most HCWs either had a well-covering shoe but not fluid-resistant or fluid-resistant but not well covering, or the shoes were neither well covering nor fluid resistant. This study did not find out the reason so this can require further study.

\section{Strengths}

This study managed to observe $100 \%$ of sample size as planned. Despite that other HCWs refused to participate, those who did participate did not drop out or withdraw their consent. $80 \%$ of the wards were visited by the investigators which shows a good representation of QECH. Most findings of this research were similar to findings in similar studies. The research achieved its objectives.

\section{Limitations}

This study has potential limitations. First some wards had few HCWs which made it difficult to reach the targeted $6 \mathrm{HCWs}$ per ward. This limited the investigators to observe similar patient care procedures. Second since sample size calculations were not sensitive to different health professions, numbers of observed participants were less in some professions which makes the results not a true reflection of their profession. Third some HCWs were left still wearing some of the PPEs after the procedure hence they were not assessed on PPE removal and hand hygiene afterwards. Fourth there was a time limiting factor since observations were made in just one week. Lastly, since the participants were aware that they were being observed so some might have displayed behaviour that was different from what they do every day hence there may have been an observation bias.

\section{Implications}

This study has revealed unavailability and inaccessibility of PPEs in wards and very poor compliance of PPE usage among HCWs at QECH. This information can be used to predict that adherence levels to PPE usage will continue to 
be low and there will be a high risk of HAIs. There is a need to implement change in order to prevent infections and ensure safety.

\section{Recommendations}

Based on the findings of this research, we recommend the following:

In-service and refresher training of HCWs on proper usage of PPEs to be carried out with new HCWs and every 3 years for refresher training. This can be arranged in form of workshops which can involve randomly picked HCWs of different professions from different wards. While it is ideal to have all HCWs trained but if not possible, the trained HWCs can become focal persons on infection prevention. The Ministry of Health has a national responsibility of ensuring quality health service delivery so it is to training HCWs in infection prevention. Individual institutions are also responsible for training their staff members.

Incorporating training of PPE usage in the curriculum of colleges training HCWs. Medical Nursing and Physiotherapy students have to be taught protocols in infection prevention. A module on SPs has to be introduced the academic year the students are starting clinical practice. Training institutions are responsible for training lecturers to be competent in infection prevention for transferring of knowledge and skills to students.

Formulation of policies and guidelines by the Ministry of Health on the proper use of PPEs which should be available in the wards.

Formulation of a committee on infection prevention and active supervision on SPs. This committee should include wide representation from relevant departments and health professions, for example, management, physicians, nurses, allied HCWs such as physiotherapists, and non- medical personnel. The committee must have a reporting relationship directly to either administration or the medical staff to promote program visibility and effectiveness 12 .

Further research on factors influencing compliance of SPs. This will give an insight into why adherence to proper usage of PPEs is low so that the issues can be appropriately addressed.

More studies investigating how to improve PPE usage.

More studies with larger sample sizes for the low represented professions like physiotherapists.

\section{Conclusion}

This study identified areas which needed improvement in healthcare system delivery regarding SPs with emphasis on PPE. Improvements in training during professional college education and in-service refresher training could improve compliance with appropriate use of PPE for relatively low cost. Management support could improve availability and accessibility of PPE in the wards at QECH, with active supervision to improve adherence levels to PPE usage.

\section{Conflict of Interest}

The researchers declare no conflict of interest. This study was approved and funded by the College of Medicine Research and Ethics Committee (COMREC).

\section{Acknowledgements}

Thanks to God the almighty for giving us the grace and mercies to carry out this study.
Our most sincere appreciation goes to the College of Medicine, University of Malawi for giving us this opportunity to study, tapping on the knowledge and wisdom of the senior lecturers; for the guidance and mentoring provided through our dedicated supervisor and lecturers. We would also like to thank the following for their constructive criticism; $\mathrm{Mr}$ Zizwani Chilinda (MSc. Global Health and Development, B.A. Health Systems Management), Mr Enock Chisati (MSc. Exercise Physiology \& Sports Science, BSc. Education in Applied Science), Mr Rueben Kalavina (MSc. Physiotherapy, BSc. Physiotherapy), Mr Anderson Mughogho (MSc. Physiotherapy, BSc. Physiotherapy) and Miss Chimwemwe Kalolo (BSc. Nursing and Midwifery).

Special thanks also go to the administrator of Queen Elizabeth Central Hospital for permitting us to access the wards and staff members working at the hospital. We also appreciate the time taken, provision of information and cooperation of the health workers who participated in this research.

We also wish to register our gratitude to the sponsor, College of Medicine Research and Ethics Committee.

\section{References}

1. Zingg W, Holmes A, Dettenkofer M, Goetting T, Secci F, Clark L, et al. Hospital organisation, management, and structure for prevention of health-care associated infection: a systematic review and expert consensus. Lancet Infect Dis. 2015;15(2):212-24.

2. Guidance for the Selection and Use of Personal Protective Equipment (PPE) in Healthcare Settings [Internet]. 2004. Available from: https:// www.cdc.gov/HAI/pdfs/ppe/PPEslides6-29-04.pdf

3. Daugherty E, Perl T, Needham D, Rubinson L, Bilderback A, Rand C. The use of personal protective equipment for control of influenza among critical care clinicians. Crit Care Med. 2009;37(4):1210-6.

4. Haile TG, Engeda EH, Abdo AA. Compliance with Standard Precautions and Associated Factors among Healthcare Workers in Gondar University Comprehensive Specialized Hospital, Northwest Ethiopia. J Env Public Health. 2017;

5. Siegel J, Rhinehart E, Jackson M, Chiarello L. guidelines for isolation precautions: preventing transmission of infectious agents in healthcare settings [Internet]. 2007. Available from: http://www.cdc.gov/hicpac/ pdf/isolation/Isolation2007.pdf.

6. Queensland Government. Infection control guidelines for personal appearance services [Internet]. 2012. Available from: https://www. health.qld.gov.au/ph/documents/cdb/infectcontrolguide.pdf.

7. Edward K, Mills C, Neo F. Current evidence regarding noncompliance with personal protective equipment - an integrative review to illuminate implications for nursing practice. ACORN. 2012;25(4).

8. Liu Y, Allen C. Nursing Super Course [Internet]. 2010. Available from: http://www.pitt.edu/ super4/40011-41001/40171.ppt.

9. Infection Prevention [Internet]. 2010. Available from: https://www. intrahealth.org/files/media/preservice-education-family-planningreference-guide/MPsFPRG-unit22.pdf.

10. Efstathiou G, Papastavrou E, Raftopoulos V, Merkouris A. Factors influencing nurses' compliance with Standard Precautions in order to avoid occupational exposure to microorganisms: a focus group study. BMC Nurs [Internet]. 2011;10(1). Available from: https://www. biomedcentral.com/1472-6955/10/1

11. Standard Infection Control Precautions [Internet]. 2010. Available from: https://www.nhsprofessionals.nhs.uk/download/comms/cg1_ nhsp_standard_infection_control_precautions_v3.pdf

12. Practical Guidelines Infection Conrol [Internet]. 2004. Available from:http://www.wpro.who.int/publications/docs/practical_guidelines 
infection_control.pdf.

13. Porto J, Marziale M. Reasons and consequences of low adherence to standard precautions by the nursing team. Rev Gaúcha Enferm. 2016;37(2):1-15.

14. Collins A. Preventing Health Care-Associated Infections. In p. 547 75. Available from: https://www.ncbi.nlm.nih.gov/books/NBK2683/ pdf/Bookshelf_NBK2683.pdf

15. Gichuhi A, Kamau S, Elijah Nyangena Z, Otieno-Ayayo N. Health Care Workers Adherence to Infection Prevention Practices and Control Measures: A Case of a Level Four District Hospital in Kenya. Am J Nurs Sci. 2015;4(2):39-44.

16. Moyo G. Factors influencing Compliance with Infection Prevention Standard Precautions among Nurses Working at Mbagathi District Hospital, Nairobi, Kenya, MSc Dissertation. University of Nairobi, Nursing; 2013.

17. Hustins W, Dente B, O'boyle C, O'Reurke E, Goldmann D. Hospital Infection prevention and control: a model for improving the quality of hospital care low and middle income countries. Infec Control Hosp Epidemiol. 1998;19(2):125-35.

18. Infection Prevention and Control Resource Guide [Internet]. 2017 Available from: https://www.physiotherapyalberta.ca/physiotherapists/ resources_to_help_you_meet_practice_standards/infection prevention_control/infection_prevention_and_control_resource_guide/ content_listing_folder_view\#levels_of_protection.

19. Flanagan E, Chopra T, Mody L. . Infection Prevention in Altenative Healthcare Settings. Infect Dis Clin North Am. 2011;21(1):271-83.

20. Allegranzi B, Nejad SB, Garcia C, Kilpatrick C, Kelley E, Mathai E. Report on the Burden of Endemic Health Care-Associated Infection Worldwide. Geneva, Switzerland. World Health Organization, Clean Care is Safer Care Team; 2014. Report No.: ISBN 9789241501507.

21. World Bank in Malawi [Internet]. 2019. Available from: https:// www.worldbank.org/en/country/malawi/overview.

22. Charan J, Biswas T. How to Calculate Sample Size for Different Study Designs in Medical Research? Indian J Psychol Med. 2013;35(2):121-6.

23. availability. In Merriam-Webster Inc; Available from: https://www. merriam-webster.com/dictionary/availability

24. Japiong K, Asiamah G, Owusu-Dabo E, Donkor P, Stewart B, Ebel $\mathrm{B}$, et al. Availability of resources for emergency care at a second-level hospital in Ghana: A mixed methods assessment. 2016;6:30-7.

25. Universal health coverage and universal access, Bulletin of the World Health Organization [Internet]. accessibility. 2013. Available from: https://www.who.int/gender-equity-rights/understanding/ accessibility-definition/en/

26. Berhe M, Michael B, Edmond M, Bearman G, Virginia R. Practices and an assessment of health care workers' perceptions of compliance with infection control knowledge of nosocomial infections. Am J Infect Control. 2005;33:55-7.

27. Aguwa E, Arinze-Onyia S, Ndu A. Use of Personal Protective Equipment among Health Workers in a Tertiary Health Institution, South East Nigeria: Pre-Ebola Period. Int J Health Sci Res. 2016;6(8).
28. Personal Protective Equipment for Infection Control [Internet]. 2018. Available from: https://www.fda.gov/medical-devices/generalhospital-devices-and-supplies/personal-protective-equipmentinfection-control.

29. Boiano J, Steege A, Sweeney M. Adherence to Safe Handling Guidelines by HealthCare Workers Who Administer Antineoplastic drugs. J Occup Environ Hyg. 2015;11(11).

30. Lakshmi APA, Jennifer G, Stanly M, Paul C. A study on personal protective equipment use among health care providers, Tamil Nadu. Int J Community Med Public Health. 2018;5(5).

31. Verbeek J, Ijaz S, Mischke C, Ruotsalainen J, Mäkelä E, Sauni R, et al. Personal protective equipment for preventing highly infectious diseases due to exposure to contaminated body fluids in healthcare staff. Cochrane Database Syst Rev. 2016;

32. Infection Prevention \& Control [Internet]. 2016. Available from: http://www.crto.on.ca/pdf/ppg/infection_control_cbpg.pdf.

33. Mondiwa M, Hauck Y. Malawian Midwives' Perceptions of Occupational Risk for HIV Infection. Health Care Women Int. 2007;28(3):209-23.

34. Luo Y, He G, Zhou J. Factors impacting compliance with standard precautions in nursing. China Int J Infect Dis. 2010;14(12):e1106-14.

35. Piai-Morais T, Orlandi F, de Figueiredo R. Factors influencing adherence to standard precautions among nursing professionals in psychiatric hospitals. Rev Esc Enferm USP. 2015;473-80.

36. Mukwato K, Ngoma C, Maimbolwa M. Compliance with infection prevention guidelines by health care workers at ronald ross general hospital mufulira district. Med J Zambia. 2009;110-6.

37. Kader N. Infection Prevention and Control Manual: King Khalid Hospital. 2013.

38. World Confederation for Physical Therapy. Infection prevention and control [Internet]. 2017. Available from: https://www.wcpt.org/sites/ wcpt.org/files/files/resources/policies/2017/PS_Infection_prevention_ control_FINAL.pdf.

39. Nevesi H, Souzall A, Medeiroslll M, Munarilv D, Ribeirov L, Tipplevi A. Safety of Nursing Staff and Determinants of Adherence to Personal Protective Equipement. Rev Lat-Am Enfermagen. 2011;19(2).

40. John A, Tomas M, Hari A, Wilson B, Donskey C. Do Medical Students Receive Training in Correct Use of Personal Protective Equipment. Med Educ Online. 2017;2(1).

41. Alice T, Akhere A, Ikponwonsa O, Grace E. Knowledge and practice of infection control among health workers in a tertiary hospital in Edo state, Nigeria. Direct Res J Health Pharm. 2013;1(2):20-7.

42. Bearman, G, Bryant, K, Leekha, S, Mayer, J, Munoz-Price, L, Murthy, R, et al. Healthcare Personnel Attire in Non-Operating-Room Settings. Infect Control Hosp Epidemiol. 2014;35(2). 